\title{
VARIAÇÃO DENOMINATIVA NA TERMINOLOGIA MÉDICA: O CASO DA GRIPE A H1N1
}

\author{
Márcio Sales Santiago*
}

\begin{abstract}
RESUMO: Pretendemos, neste artigo, observar a variação denominativa no domínio da Medicina, especialmente a que se refere ao termo gripe A H1N1. Para tanto, mostraremos, brevemente, o processo de gênese terminológica e a maneira como se dá a proliferação de novas denominações. Nosso ponto de partida é o entendimento de que os termos, além de serem componentes cognitivos das áreas de conhecimento, pois representam um saber técnico, científico e tecnológico, são, sob o ponto de vista linguísticocomunicacional, unidades das linguas naturais que, tal como as unidades lexicais, são capazes de variar.
\end{abstract}

PALAVRAS-CHAVE: Terminologia médica; Variação denominativa; Análise terminológica.

ABSTRACT: In this article we aim to observe the denominative variation in the Medical field, especially with regard to term influenza A H1N1. We briefly show the process of terminological genesis and how the proliferation of new terms takes place. Our starting point is the understanding that the terms, besides being cognitive components of knowledge areas, represent a technical, scientific and technological knowledge; under the linguistic-communicational point

* Doutorando do Programa de Pós-Graduação em Letras, Universidade Federal do Rio Grande do Sul, Brasil. Bolsista do CNPq. Pesquisador do Grupo TermiLex. 
of view, they are units of natural languages capable to vary as well as lexical units.

KEYWORDS: Medical terminology; Denominative variation; Terminological analysis.

As linguas vivas se enriquecem com o progresso da civilização, e das ciências, e uma nova ideia pede um novo termo.

(Gonçalves de Magalhães, 1836)

\section{Considerações iniciais quanto à Terminologia}

Tradicionalmente, a Terminologia é definida como a área de estudo que tem no termo seu objeto central de análise teórica e aplicada, admitindo que esse objeto é capaz de representar e transmitir o conhecimento especializado inerente das áreas técnico-científicas. Como campo de estudo, a Terminologia é um tanto quanto jovem. No entanto, segundo Rondeau (1984), os vocábulos especializados já eram utilizados pelos filósofos e pensadores gregos, para expressar ideias, e pelos comerciantes cretenses, para realizar negociações.

Isso mostra que desde muito cedo o ser humano sentiu necessidade de sistematizar a linguagem utilizada nas ciências e nas técnicas. Por uma questão de padronização, o grego e o latim foram as línguas usadas por estudiosos e pesquisadores nas chamadas nomenclaturas técnico-científicas, cujo papel era o de etiquetar unidades lexicais criadas de forma artificial, no intuito de se evitar fenômenos eminentemente linguísticos, como a sinonímia e a ambiguidade. Exemplo disso é a bactéria causadora do tétano, que recebeu a designação Clostridium tetani. Temos, portanto, uma classificação científica que, a rigor, é um sistema organizativo regido por um conjunto de regras e critérios que se pretendem universais, mas que, dada a grandiosidade do conjunto dos seres vivos e sua inerente diversidade, sofrem necessárias adaptações.

TradTerm, 16, 2010, p. 397-410 
O sistema mais antigo de classificação de seres vivos que se tem conhecimento é o de Aristóteles (384 a.C. - 322 a.C.), que classificou todos os organismos vivos então conhecidos como plantas ou animais. Ainda nesse contexto, podemos citar os relevantes trabalhos de Antoine Lavoisier (1743-1794) e Carl Von Linné (1707-1778), ambos no século XVIII, os quais, respectivamente, criaram uma nomenclatura das substâncias químicas semelhante a que ainda está em uso nos dias de hoje, e uma organização da moderna sistemática de classificação para plantas e animais, conhecida atualmente como nomenclatura da Botânica e da Zoologia.

Nessa perspectiva, o vertiginoso progresso científico, o desenvolvimento da tecnologia e dos meios de comunicação, bem como a aproximação das nações por meio de relações politicas e comerciais, tornaram-se fatores determinantes para o crescimento da ciência terminológica e, consequentemente, de seus inventários, à medida que os termos transmitem conceitos e designam paradigmas dos domínios especializados, tanto no âmbito da linguagem como no âmbito socioeconômico, o que significa dizer que não há expressão de conhecimento especializado sem terminologia ${ }^{1}$.

Feitas essas considerações iniciais, este artigo terá como enfoque principal a análise do termo gripe A H1N1 sob o prisma da variação terminológica. Para tanto, julgamos indispensável apresentar, inicialmente, a relação que existe entre a Terminologia e a Medicina.

\section{Terminologia e Medicina}

A Terminologia, como ciência teórica e aplicada, surge a partir da iniciativa do engenheiro austríaco Eugen Wüster (1898-

1 Faz-se necessária uma diferenciação, a qual tomamos emprestada de Krieger (2001): Terminologia com "T" maiúsculo e "t" minúsculo. A primeira se refere ao campo de estudo; a segunda é usada para indicar os conjuntos de termos. 
1977) em normalizar e normatizar ${ }^{2}$ a linguagem da Eletrotécnica. A ideia de Wüster, proposta na base da Teoria Geral da Terminologia (TGT), é a de que a comunicação, em âmbito técnicocientífico, deveria acontecer de forma limpa, sem ruídos. Isso significa rejeitar fenômenos linguísticos presentes em qualquer língua natural, como sinonímia, variação, polissemia e ambiguidade, uma vez que para ele o conceito de variação linguística estava associado a uma perturbação da unidade linguística.

A exatidão no nível conceitual (monorreferencialidade), tanto quanto a noção de exclusividade denominativa (univocidade), em que cada termo deveria designar apenas um conceito, são as condições ideais para uma padronização, que visa a garantir a perfeita comunicação científica e técnica em nível internacional. No interior da TGT está o pensamento de que o termo é uma unidade cognitiva, em que cada unidade representa um conhecimento específico dentro de um domínio de especialidade. Contudo, em decorrência do amadurecimento dos estudos terminológicos, novas concepções sugiram.

Primeiramente, a observação inicial que se fez do termo apenas o apontava como a principal unidade de estudo da Terminologia e como nódulo conceitual de um determinado campo de saber. No entanto, posteriormente, foi admitido que esse objeto também assume uma face linguística, já que é passivel de admitir outros modos de representação da linguagem, ideia rebatida pelo modelo wüsteriano. Essa nova feição mostra que os termos são componentes das línguas naturais, uma vez que são suscetiveis aos fenômenos de variação.

De la Torre (2004), Boulanger (1982; 1991) e Auger (1993) discutiram em seus trabalhos uma noção de Terminologia direcionada para o social, como forma de atenuar os princípios de padronização impostos pela TGT. Esta noção, a qual se denominou Socioterminologia, foi tratada com mais particulari-

2 Em Krieger e Finatto (2004:39) encontramos a distinção entre normalizar e normatizar: "Normalizar compreende aparelhar as linguas para todas as formas de expressão, sobretudo a expressão técnico-científica. Normatizar diz respeito à fixação de uma determinada expressão como a mais adequada."

TRADTERm, 16, 2010, p. 397-410 
dade por Gaudin em sua tese de doutoramento. Nela, o autor nos diz que:

a socioterminologia, com o suposto de que deseja ultrapassar os limites de uma terminologia "de escrivão", deve localizar a gênese dos termos, sua recepção, sua aceitação, mas também as causas do insucesso e as do sucesso, no âmbito das práticas linguísticas e sociais concretas dos homens que empregam tais termos. (Gaudin, 1993:216)

É possivel percebermos que essa corrente da Terminologia é contrária à análise in vitro dos termos, propondo que estes sejam analisados a partir de uma observação in vivo das linguagens de especialidade, respeitando a variação, principal ponto que norteia seu desenvolvimento.

O reconhecimento da existência de outras formas de representação denominativa dentro da comunicação especializada implica a noção de que uma linguagem de especialidade não é um subconjunto estruturalmente homogêneo, mas um conjunto de variedades em função dos usos e situações comunicativas reais, visto que a categorização das unidades lexicais especializadas está relacionada ao universo cultural em que os indivíduos estão inseridos. Dessa forma, temos a noção de que o termo é muito mais do que apenas um elemento cognitivo que representa uma determinada área do conhecimento. É necessário entender que,

se a Terminologia, como campo de conhecimento, toma o termo como objeto primeiro de investigação, precisa deixar de vê-lo como um bloco monolítico, mas observá-lo na especificidade de suas realizações linguísticas, cognitivas, discursivas e ainda em sua dimensão pragmático-social. (Krieger, 2009:139)

Assim, constatamos o que fora dito anteriormente acerca do desenvolvimento da Terminologia, bem como de outras ciências, como é o caso da Medicina. A esse desenvolvimento, podemos associar o avanço das tecnologias da informação, o que leva a um aumento na divulgação do conhecimento especializado, 
nesse caso de termos e conceitos oriundos do conhecimento médico, outrora restritos a laboratórios de pesquisa e corredores universitários.

Na sociedade de hoje, o contato com o conhecimento deixou de ser exclusivo aos especialistas, passando a estar presente no dia a dia do leigo. Tal fato revela uma consequência imediata dessa evolução técnica, científica e tecnológica: a presença cada vez maior de um elevado número de conceitos na vida das pessoas em geral, implicando a criação de novos termos.

Sob essa perspectiva, torna-se dificil imaginar algum ramo da ciência que não possua seus termos, razão pela qual Borges expressa que,

na verdade, não existe ciência encerrada em si mesma, sem formas próprias de expressão. É necessário, então, comunicar ciência. E mais uma vez, a língua, sob um figurino especializado, é a protagonista que desempenha o papel de ajudar a escrever ciência. Explica-se, assim, também, o papel das terminologias na expressão dos saberes humanos. (Borges, 1998:142)

Isso significa dizer que a origem da terminologia de um dado campo de conhecimento é tratada, segundo Benveniste (1989:252), como um dos "acontecimentos mais importantes de sua evolução", visto que todos os movimentos advindos do pensamento científico são expressos através de seus termos.

Por sua vez, a Medicina, como uma das mais antigas e sedimentadas áreas do conhecimento humano, desenvolveu, $a$ priori, uma linguagem de difícil compreensão, repleta de particularidades. O fato de a maior parte de sua terminologia ter sido regularmente formada a partir de radicais gregos e latinos, a exemplo de oncologia e trombocitopenia, representa uma tentativa de alcançar o máximo de exatidão no significado, contribuindo para uma troca comunicativa eficiente dos conhecimentos científicos entre cientistas de diferentes países, línguas e culturas.

Apesar do hermetismo característico da linguagem médica, atributo típico das áreas clássicas, sua terminologia não es-

TradTerm, 16, 2010, p. 397-410 
capa do fenômeno da variação linguística. Esse fato é destacado por Sournia, no prefácio da obra Vocabulaire du discours medical: structure, fonctionnement, apprentissage, de Joseph Ghazi:

Uma doença pode ter recebido muitos nomes, porque o anatomista lhe atribui como característica principal as lesões que vê em seu microscópio, enquanto que o biólogo a descreve segundo os fenômenos que revela em seu laboratório e o clínico, por sua vez, preocupa-se com os sintomas que deve tratar etc. Por isso um nome não prevalece sobre outro, porque ele corresponde a um tipo de conhecimento particular, complementar e não contraditório. (Sournia, 1985:06 apud Delvizio\&Barros, 2008:1407)

Em face disso, a multiplicação de denominações pode mesmo vir a tornar-se um problema na interação, ocasionando, segundo Cabré (1993), dificuldades na comunicação entre especialistas e seus pares.

Gutiérrez Rodilla (2005), entretanto, afirma que a terminologia da saúde, especialmente a da Medicina, apresenta peculiaridades e problemas, dentre os quais se destacam a falta de reciprocidade nas relações que se estabelecem entre profissionais e usuários de sistemas de saúde. Isso ocorre principalmente em relação ao leigo, para quem o termo é de difícil apreensão, muitas vezes não fazendo sentido, já que o conteúdo especializado não faz parte de seus conhecimentos. Logo, ao se deparar com um termo médico, ele tem a nítida sensação de estar adentrando em uma nova linguagem, repleta de "palavras" e "expressões" desconhecidas, razão pela qual prefere utilizar os chamados termos populares, citados nas ruas e nos meios de comunicação, passando estes a coexistir diretamente com a terminologia científica ${ }^{3}$.

3 Essa realidade pôde ser explicitada em nossa dissertação de mestrado, na qual examinamos artigos que compõem um site de divulgação científica da saúde, mostrando que os termos da Medicina coocorrerem diretamente com as terminologias ditas populares, a exemplo de toxoplasmose/doença do gato, hepatite C/amarelão, nefrolitíase/pedra nos rins. A convivência entre as denominações técnico-científicas e as de 
Sem a pretensão de avançar mais nesse ponto, passamos imediatamente ao foco deste trabalho: o exame da variação terminológica da gripe A H1N1.

\section{O caso da gripe A H1N1}

Desde sua divulgação mundial em abril de 2009, a gripe $A$ H1N1 ganhou enorme espaço nos diversos tipos de mídia e sua ampla divulgação proliferou várias denominações. O que almejamos agora é expor os termos utilizados para denominar a doença até o presente momento ${ }^{4}$, seguidos de pequenas análises de fatos que pensamos ter contribuído para se atribuir tais designações.

Primeiramente, a doença foi chamada de gripe suina, visto que foi causada por vários tipos de gripe que frequentemente infectam os porcos. De imediato, os produtores brasileiros e mundiais sentiram a queda na comercialização da carne de porco e de seus derivados. No entanto, pouco depois foi comprovado que a doença somente circula entre seres humanos, sendo transmitida de pessoa infectada para pessoa não infectada via contágio direto. Diante disso, os produtores de carne de porco pressionaram os governos e a Organização Mundial da Saúde (OMS) para que fosse retirado o adjetivo suina da denominação. Assim, pode-se dizer que o medo de ficar estigmatizado, bem como a reação da população contra os animais, foram fatores decisivos para que a OMS recomendasse o uso do termo científico H1N1 em detrimento do popular gripe suina. Pouco tempo depois, a mesma instituição decidiu renomear a doença para novo $H 1 N 1$, o que revela dificuldades da principal agência de saúde do mundo em denominar a doença.

Vale frisar: o uso do termo gripe suina pode ser comparado ao termo utilizado em 1997, quando um surto de gripe provoca-

caráter socioterminológico nos motivou a propor mecanismos de busca e recuperação de informações especializadas, os quais denominamos de "redes de palavras-chave". Estas, por seu turno, têm como principal objetivo auxiliar o leitor dos artigos de divulgação a entender melhor os termos e, consequentemente, os conceitos advindos do discurso médico. $4 \quad$ Setembro de 2009.

TradTerm, 16, 2010, p. 397-410 
do pela mutação do vírus $H 5 N 1$ assolou parte da Ásia. Esse vírus já era conhecido, porém apenas em aves e, por essa razão, a doença ficou conhecida mundialmente como gripe aviária ou gripe das aves. Um processo de mutação o tornou transmissivel para os humanos; mesmo assim isso provocou o sacrificio de mais de 1,5 milhões de aves. Foi justamente o que aconteceu com a gripe A H1N1, quando muitos porcos também foram sacrificados em todo o mundo.

Quase concomitante ao uso do termo gripe suina, usouse, no início da epidemia, a denominação gripe mexicana, pois foi no México onde surgiram os primeiros casos e as primeiras mortes. O governo mexicano interveio e protestou perante as autoridades para que o termo não fosse usado, por compreender que isso poderia causar enorme prejuízo ao país. Do mesmo modo que o adjetivo suina, a OMS decidiu retirar também o adjetivo mexicana, recomendando, além do termo novo $H 1 N 1$, outros dois: gripe A H1N1 e influenza A H1N1, ambos referentes à denominação científica do vírus.

Cabe, aqui, outro regaste histórico. A gripe que ocorreu em 1918 ficou conhecida em todo mundo como gripe espanhola ou influenza espanhola ${ }^{5}$. Na época, uma pandemia incomum e mortal causada pelo vírus influenza A H1N1, o mesmo de agora, espalhou-se por quase todo mundo. O local de origem da doença ainda é desconhecido, mas segundo Bertucci-Martins (2004), ela provavelmente se originou nos campos de treinamento militar no interior dos Estados Unidos. Entretanto, a denominação da moléstia passou para a história como gripe espanhola, o que ocasionou uma ampla discussão entre os médicos da época. O fato de a Espanha não ter participado da Primeira Guerra Mundial e de a imprensa espanhola noticiar aberta e livremente que pessoas e soldados em muitos lugares do mundo estavam adoecendo e morrendo em números alarmantes, pode ter contribuído para uma fixação desse termo, provocando a falsa impressão de que a doença fazia mais vitimas naquele país.

Diante desse quadro, podemos notar que o vírus causador da doença não é novo, visto que há 91 anos ele se manifestou,

5 Foi designada também por gripe pneumônica, peste pneumônica e pneumônica. 
provocando uma pandemia. Apesar desse acontecimento e aproveitando a deliberação da OMS em chamá-lo de novo H1N1, a mídia criou a denominação nova gripe para se referir à doença que mais uma vez se apresenta, já que para o leigo é mais fácil compreender um termo amplamente divulgado (gripe) em detrimento a outro de caráter eminentemente científico (H1N1). Consideramos, ainda, que essa criação terminológica reflete a ideia de que a doença é nova e, principalmente por não haver vacina ${ }^{6}$, todos os cuidados devem ser tomados para evitá-la. Outro fator que pode ser inferido é que OMS e mídia criaram um termo "politicamente correto" para evitar constrangimentos com o governo e o povo mexicano e com produtores de carne suína, geralmente grandes anunciantes.

Dito isso, compete-nos, agora, mostrar os termos menos especializados e os mais especializados, considerando-se a perspectiva de registros funcionais, baseada em um continuum referente aos graus de especialização (Schröder, 1991; Ciapuscio, 2003), conforme a figura abaixo:

$(-)$

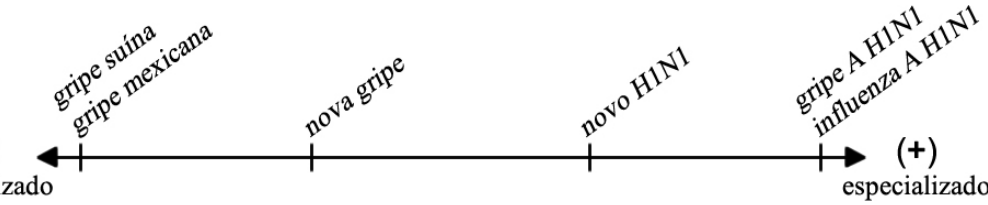

Figura 1: Localização dos termos no continuum

É importante ressaltar que o termo gripe suina, denominação menos especializada, aparece com muita frequência nos meios de comunicação, pois parece ser o termo de maior alcance entre os leigos, o que pode ser explicado pelo fato de ter sido o primeiro a ser veiculado. Isso, porém, é apenas uma especulação, já que é necessária uma análise mais detalhada do fenômeno.

Por seu turno, os termos gripe A H1N1e influenza A H1N1, recomendados pela OMS, são as denominações mais utilizadas

6 Até setembro de 2009, época em que este artigo foi escrito, não havia vacina no Brasil, mas testes já estavam sendo realizados no mundo.

TradTerm, 16, 2010, p. 397-410 
pelo Ministério da Saúde (MS), secretarias estaduais e municipais de saúde em comunicações destinadas ao público em geral e à mídia, sob a forma de pronunciamentos à nação, vídeos na internet, entrevistas e notas à imprensa ${ }^{7}$. Já nos informes técnicos, chamados pelo MS de "boletins epidemiológicos", os quais são destinados principalmente aos profissionais de saúde, o órgão usa o termo nova influenza $A$ (H1N1). Frequentemente, são também utilizadas as formas reduzidas gripe A e influenza A.

Um outro fato que foi percebido refere-se às diferentes formas como o termo é grafado. Encontramos três grafias distintas: todas as letras e números juntos: $A H 1 N 1$; o tipo separado da composição por espaço: A H1N1; e o tipo separado da composição por parênteses: $A$ (H1N1). Esse dado, que pode parecer banal, mostra bem que há variação inclusive de natureza ortográfica no uso do termo. Entretanto, tal observação pode ser valiosa para um estudo linguístico-descritivo do uso dessa terminologia.

Por fim, chamamos atenção para o fato de que com o surgimento da denominação nova gripe, a gripe "convencional" recebeu o adjetivo comum, passando a ser designada por gripe comum, na intenção de diferenciá-la da nova enfermidade.

\section{Considerações finais}

Quisemos, com este artigo, mostrar o fenômeno da variação denominativa na área da Medicina, exemplificando-a com o caso da gripe A H1N1. Expor a diversidade de denominações que coexistem em relação a esse termo é reconhecer o caráter variacionista que tais unidades assumem em contextos sociodiscursivos especializados.

Compreendida como um modo de representação das línguas naturais, a variação é mais intensamente observada no âmbito denominativo, fazendo-se presente em todas as manifes-

7 Os documentos, pronunciamentos, vídeos e demais informações ao cidadão e ao profissional e gestor da saúde podem ser encontrados no portal do Ministério da Saúde (http:// portal.saude.gov.br) e em http:/ / www.respostasgripesuina.com.br. 
tações linguísticas autênticas. Por esse aspecto, pode ser descrita e analisada cientificamente.

Diante disso e a título de breves conclusões, podemos dizer em ralação ao caso observado que o MS, as secretarias estaduais e municipais de saúde, bem como as instituições privadas dão preferência aos termos influenza A (H1N1) e gripe A (H1N1), além de suas reduções, em campanhas de esclarecimento à população. Todavia, em vídeos de divulgação e esclarecimento à população disponibilizados no site do MS e veiculados em rádio, televisão e internet, os termos gripe suina e nova gripe figuram algumas vezes nas perguntas feitas pelos cidadãos, no discurso do próprio ministro da saúde e dos especialistas, assim como em alguns títulos de vídeos e páginas web.

Em meio a toda essa variedade terminológica, a mídia, não obstante à recomendação da OMS e apesar de ter criado o termo nova gripe, que consideramos "politicamente correto", usa assiduamente o termo gripe suína, devido à grande divulgação que tal denominação alcançou. Acreditamos que este último é o termo consagrado pelos usuários da língua portuguesa no Brasil quando se referem à doença.

Finalmente, esperamos ter apresentando alguma contribuição no que refere ao estudo da Terminologia, especialmente no que diz respeito ao aspecto da variação denominativa no campo da Medicina.

\section{Agradecimento}

Agradeço às professoras Maria da Graça Krieger (UNISINOS) e Sabrina Abreu (UFRGS) pelas observações críticas que fizeram à versão preliminar deste artigo.

\section{Referências}

BENVEniste, E. (1989) Problemas de linguística geral II. Campinas: Pontes.

BERTUCCI-MARTINS, L. M. (2004) Fragmentos do discurso científico na gripe espanhola. Anais do XVII Encontro Regional de História da 
ANPUH. São Paulo: ANPUH, pp. 1-9. Disponivel em <http://www. anpuhsp.org.br/downloads / CD\%20XVII / ST\%20III/Liane\%20 Maria\%20Bertucci-Martins.pdf> Acesso em 11 de julho de 2009.

BORGES, M. F. (1998) Identificação de sintagmas terminológicos em Geociências. Dissertação de Mestrado em Letras, Porto Alegre: Universidade Federal do Rio Grande do Sul.

BRASIL. Ministério da Saúde. Influenza A H1N1 - informações para o cidadão. Disponível em: <http://portal.saude.gov.br/portal/saude/ area.cfm?id_area=1616>. Acesso em 11 de julho de 2009.

Influenza A H1N1 - informações para o profissional e o gestor. Disponivel em <http://portal.saude.gov.br/portal/saude/profissional/ area.cfm?id_area=1534>. Acesso em 11 de julho de 2009.

CABRÉ, M. T. (1993) La Terminología: teoría, metodología, aplicaciones. Barcelona: Antártida/Empúries.

CIAPUSCIO, G. E. (2003) Textos especializados y terminología. Barcelona: IULA.

DE LA TORRE, M. M. S. (2004) Análisis constrativo de la variación denominativa en textos especializados: del texto original al texto meta. Tese de Doutorado em Linguística Aplicada, Barcelona: Universidade Pompeu Fabra.

DELVIZIO, I. A.; BARROS, L. A. (2008) Processos de criação lexical na terminologia médica: das ruas aos laboratórios. In: MAGALHÃES, J. S.; TRAVAGLIA, L. C. (org.) Múltiplas perspectivas em Linguística. Uberlândia: UFU, pp. 1404-1411.

ESCLAREÇA SUAS DÚVIDAS SOBRE A GRIPE SUÍNA. Disponivel em: $<$ http:/ /www.respostasgripesuina.com.br/>. Acesso em 31 de julho de 2009.

GAUDIN, F. (1993) Socioterminologie: des problèmes semantiques aux pratiques institutionnelles. Rouen: Publications de l'Université de Rouen.

GUTIÉRREZ RODILLA, B. M. (2005) La medicina, sus mundos y sus lenguajes. In: CABRÉ, M. T.; BACH, C. (eds.). Coneixment, llenguatge $i$ discurs especialitzat. Barcelona: IULA/ Universitat Pompeu Fabra, pp. 131-140.

KRIEGER, M. G. (2009) Terminologia técnico-científica em espaço público: que terminologia é essa? Revista da ANPOLL, vol. 1, n. 26, pp. 130-145.

(2001) Terminologia técnico-científica: seu papel no Mercosul. Boletim da Associação Brasileira de Linguística, n. 24, fev. Disponí- 
vel em <http:/ / www.unb.br/abralin/index.php?id=8\&boletim=24\& tema $=02>$ Acesso em 23 de maio de 2006.

KRIEGER, M. G.; FINATTO, M. J. B. (2004) Introdução à Terminologia: teoria e prática. São Paulo: Contexto.

GONÇALVES DE MAGALHÃES, D. J. (1965) [1836] Suspiros poéticos e saudades. Rio de Janeiro: Herdersche.

RONDEAU, G. (1984) Introduction à la Terminologie. Québec: Gaëtan Mourin.

SANTIAGO, M. S. (2007) Redes de palavras-chave para artigos de divulgação científica da Medicina: uma proposta à luz da Terminologia. Dissertação de Mestrado em Linguística Aplicada, São Leopoldo: Universidade do Vale do Rio dos Sinos.

SCHRÖDER, H. (1991) Subject-oriented texts: languages for special purposes and text theory. Berlin: Walter de Gruyter.

TradTerm, 16, 2010, p. 397-410 